\title{
Role Of Culture And Self Esteem On Loneliness In Indians Shifted To USA And Indigenous Indians
}

\author{
Neha Dalal \\ Assistant Professor, Department of Psychology, L.S Raheja College of Arts \& Commerce, Mumbai. \\ Corresponding author: Neha Dalal \\ Email-neha.dala1@1sraheja.org
}

\begin{abstract}
Background: The purpose of the study was to investigate the relationship between self-esteem and loneliness scores in individualistic culture and collectivistic culture.

Methods: Through the convenience sampling method, 50 participants chosen were Indians who had shifted to United States of America and 57 participants chosen were Indigenous Indians. The age group of the sample was between 17 to 25 years. They were administered Self-Esteem Scale (Rosenberg, M; 1965) and UCLA Loneliness Scale (Russell, D, Peplau, L. A.. and Ferguson, M.L.; 1978). On the basis of Self Esteem scores the participants were divided into groups of two, high self-esteem and low self-esteem and their loneliness scores were compared. A two-way ANOVA for Randomized design was used to find if there was a significant difference in the loneliness scores of the four groups.

Results: Results indicated that participants who had shifted to individualistic culture from collectivistic culture had higher loneliness scores and participants with low self-esteem has higher loneliness score. There was significant interaction effect, which indicated that participants with low self-esteem in individualistic culture had the highest loneliness scores, however for participants in collectivistic culture, high self-esteem scores was associated with more reported loneliness than participants with low self-esteem scores.

Conclusion:It is concluded from this study that in this sample, Indians in USA reported feeling more lonely than Indigenous Indians, while participants with lower self-esteem reported feeling lonelier than individuals with high self-esteem, with interaction effect whereby people with high self-esteem actually reported feeling more lonely in Indian than people with low self-esteem.
\end{abstract}

Keywords: Self-esteem, Loneliness, Individualistic culture, Collectivistic culture.

(Paper received $-2^{\text {nd }}$ January 2018, Peer review completed $-10^{\text {th }}$ January 2018)

(Accepted $-12^{\text {th }}$ January 2018)

\section{INTRODUCTION}

Authors say that loneliness is a subjective state reflecting the fact that the quality and quantity of relationships wanted is lower than the quality and quantity of relationships available. Many philosophers have described loneliness as "malignant solitude" or a pervasiveness of "desolate loneliness", and it has been argued that "the drive to avoid a sense of isolation actually constitutes the dominant psychic force underlying all human consciousness and conduct"[1]. Mijuskovic describes that loneliness also involves the cognitive awareness of this deficiency in personal and social relationships and this in turn leads to subjective feelings of despair and a desire for more intimate relationships [2]. Blazer furthers this discrepancy between the desired and the actual quality and quantity of relationship can be chronic or may be triggered by change in the social situations like moving to another place or change in the social needs [3]. 
Loneliness is different from aloneness. In their book, Asher and Paquentt defined aloneness as the state of having no people around, not necessarily physically but also with no one to communicate with. Solitude, however is a voluntary aloneness and desired state denoting the absence of people [4]. Moustakas [5], a researcher, says that while loneliness may be experienced even with people around, solitude is actual absence of people, which is desired as it facilitates redirecting inner resources to understand self, learning to enjoy own company, and using the time to make plans for various requirements in life.

A distinction can also be made between social and emotional loneliness. Social loneliness is when a person does not have relationships with groups of friends, because they lack network of social ties and acquaintances. Russell, Cutrona, Rose and Yurko describe emotional loneliness as a state when an individual has no close and intimate attachments to another person, or lack of closeness in intimate relationships, producing a feeling of emptiness and anxiety [6]. Almost everyone feels loneliness at some point in their lives. For most, this distressing subjective experience is short lived. For some however the effects are long lasting and severe.

\section{Correlates of loneliness}

Loneliness is often associated with depression, anxiety, unhappiness and shyness [7]. Loneliness is also found to be associated with obesity and smoking [8]. College students tend to suffer more from loneliness than any other age group, as this is the time they have loosened ties with their parents and are actively seeking intimacy with their peers, especially of the opposite sex [9]. Attachment styles and experiences with parents during childhood are also found to be correlated to likelihood of developing feeling of loneliness [10]. People with low self-esteem tend to experience loneliness more than people with high selfesteem. Self-esteem is "the judgement we make about own worth and feelings associated with those judgements" [11]. The reason for this maybe that people with low self-esteem do not construe feedback from others as positive always.

Culture affects loneliness too. Certain individualistic cultures like America where emphasis is on personal fulfillment often at the expense of stable relationships, loneliness is higher. In one international study of immigration, Ward and Searle found that culture distance predicted the mood disturbance, whereby Canadian students were less likely to be lonely than Nigerian students who immigrated to America [12]. Triandis [13] devised a test that examines what he calls Cultural syndromes; "a pattern of shared attitudes, beliefs categorizations, self-definitions, norms, role definitions and values that is organized around a theme that can be identified among those who speak a particular language, during a specific historic period, and in a definable region". One definable cultural syndrome is collectivistic and individualistic culture. People socialize their children differently in these two kinds of cultures. In collectivistic culture, Kohn emphasises on obedience, tradition, conformity, duty and sacrifice for the group. In individualistic culture it is on independence, self-reliance, privacy, exploration, creativity, and non-conformity. In collectivistic cultures, people receive more social support from their groups [14]. However if individual does not confirm to the in-group the punishment is severe. While in individualistic culture, person does not receive much social support but is free to do whatever she wishes. In collectivistic cultures people do not develop good skills for entering new groups.

Collectivistic perceive many social behaviors as more intimate than do individualistic. Individualistic place self in the front of the perceptual field and relationships in the background of the field. Collectivistic place relationships in the front and themselves in the background [15]. Loneliness is not much of a problem in collectivistic culture, however it is more prevalent in individualistic cultures. Marcus and Krishnamurthy [16] found that members of individualistic cultures communicated with the goal to express personal ideas, while the intention of the individuals from collectivistic cultures is to maintain interpersonal relationships.

Collectivistic and individualistic cultures can also be differentiated further whereby ones emphasizing hierarchy - called vertical and cultures emphasizing equality - called horizontal. Horizontal Individualistic cultures (HI) such as Australia and Sweden where people want to be independent and unique and happy to do their own thing, but not necessarily want to be better than others. [17]. Vertical individualistic (VI) cultures such as those of corporate America that emphasize both uniqueness and status differentiation. In such cultures one must become "the best" and people become offended when anyone suggests to them that they are average [18]. They want to be independent but also want to win competitions, to be best, be 
distinguished. In horizontal collectivistic cultures (HC) individual is lost in the roup like Israeli Kibbutz. Vertical collectivistic cultures (VC) such as China and India, the individual is relatively unimportant in relation to the authorities of the group. The individual is expected to sacrifice themselves for the group, to obey and confirm.

Various studies have shown that this differentiation between cultures is useful and vertical collectivist are different from horizontal collectivists and Vertical Individualists and different from horizontal individualists.

\section{Statement of problem}

Loneliness research exponentially expanded with the development of loneliness scale by Russel, Peplau et al. Out of the various correlates of loneliness as already mentioned above, culture and self-esteem were of particular interest to the researcher. With regards to culture, studies have been done to find if individualistic cultures have more loneliness reported than collectivistic cultures. Also migration studies, such as those by Nah, have been done to find if transition in geographical locations and entering a new culture increases reports of loneliness. Entirely separate studies of self-esteem and loneliness have also been done. This study was to find out role of the two variables cultural migration and of self-esteem in reported loneliness, and if any interaction effect of the two variables.

A study done to investigate the relationship between loneliness, self-esteem, self-efficacy and gender was done on United Arb Emirates students. A stratified sampling procedure was used to choose 495 students. Scales used were Revised UCLA loneliness scale, Rosenberg Self-esteem scale, General self-efficacy scale. Results showed that females reported more loneliness than males and lower self-esteem and lower selfefficacy were associated with higher levels of loneliness. Self-esteem was the significant predictor of loneliness [19]. 285 Chinese college students answered the questionnaire on self-esteem, social anxiety and loneliness. Results found that social anxiety was the mediating factor between self-esteem and loneliness [20]. Study of 196 American Indian Adolescents found that social support was a strong predictor in resilience followed by self-esteem and subjective well-being [21].

\section{METHODOLOGY}

\section{Data Analysis Strategies}

Participants in both countries were administered Self-Esteem Scale and UCLA Loneliness Scale. The range of scores from self-esteem scale showed no extreme scores in either of the participant groups. Hence Median of self-esteem scores was used to divide the participants further into two groups of high self-esteem and low self-esteem. Online Statistical site- Vassar net and Student version of SPSS was used to analyze the data.

\section{Participants}

The Current study employed Convenience sampling method to choose 40 Indian participants who had shifted to United States of America from India. 50 participants chosen were from India. All participants were between the age group of $17-25$ years. Since the study was about shift in culture from collectivistic to individualistic, second generation Indians in United States were excluded from the study.

\section{Materials Used}

Self-Esteem Scale [22]: The Rosenberg Self Esteem Scale developed by Dr. Morris Rosenberg (1965) is the most widely used unidimensional scale to measure global self-worth, self-liking and self-confidence. It is a 10 item scale. It uses a 4 point Likert type rating scale format ranging from "Strongly agree" to "Strongly disagree". Five of the items have positively worded statements and five negatively worded statements. Scores for items 2, 5, 6, 8, and 9 are reversed. Hence the above mentioned items are scored- 1 point for "strongly disagree", 2 points for "disagree", 3 points for "Agree" and 4 points for "strongly agree" It is a summative scale and hence all points assigned to each item are added up. Higher scores indicate higher self-esteem. Reliability of the scale is high with a test re test correlation from 0.85 to 0.72 for 2 week interval and correlation of 0.82 for 1 week interval. The reported Cronbach's Alpha for internal consistency for this Scale ranges from 0.82 to 0.88 . 
UCLA Loneliness Scale [23] - University of California Los Angeles Loneliness Scale was developed by Russel, Peplau and Ferguson. Developing the measure of loneliness. Journal of Personality assessment, 42(3): 290-294) so as to determine the loneliness level of the person. UCLA Loneliness Scale is composed of 20 items, and participants rate their agreement from 1 (not at all true of me) to 4 (very true of me) on a 4-point Likert-type scale. It is a summative scale whereby all the scores are added to obtain one score. The higher the score is, the higher level of loneliness is. Cronbach's alpha coefficient is reported as ranging from 0.89 to 0.94 across samples and test-retest reliability is 0.73 and re-test correlation coefficient is 0.73 . The scale was adapted into Turkish by Demir. Demir has found that Cronbach Alpha internal consistency coefficient of the scale to be 0.96 and re-test correlation coefficient after five weeks was found to be 0.94 .

\section{Design and hypothesis}

The loneliness scores of four groups were compared, the groups being Indians shifted to USA with high self-esteem, Indians shifted to USA with low self-esteem, Indigenous Indians with high self-esteem and indigenous Indians with low self-esteem. Hence it is a $2 \times 2$ randomized design.

Following null hypothesis were stated

1. There is no significant difference in the loneliness score of Indians who shifted to USA and Indigenous Indians

2. There is no significant difference in the loneliness score of participants with low self-esteem and participants with high self-esteem

\section{Statistics}

Test of homogeneity and Test of normality were done to justify the use of parametric tests for sample size less than 30 in each condition

After the justification of usage of parametric test, 2 way ANOVA for randomized design was used to find if the difference between the two conditions was significant.

\section{RESULTS}

Table 1 - Test of normality for score distribution for Indians in USA and Indigenous Indian

\begin{tabular}{|c|c|c|c|c|c|}
\hline \multirow{2}{*}{ Loneliness } & Country & \multicolumn{3}{|c|}{ Shapiro-Wilk } & \multirow{2}{*}{} \\
\cline { 3 - 5 } & $\begin{array}{c}\text { Indians in } \\
\text { USA }\end{array}$ & 0.1 & 0.961 & 50 & 0.097 \\
\cline { 2 - 5 } & Indians & 0.143 & 0.946 & 57 & 0.082 \\
\hline
\end{tabular}

Table 2 - Test of normality for score distribution for High Self-esteem and Low self esteem

\begin{tabular}{|l|l|c|c|c|}
\hline \multirow{2}{*}{ Self_Esteem } & \multicolumn{3}{|c|}{ Shapiro-Wilk } \\
\cline { 3 - 5 } & & Statistic & df & Significance \\
\hline \multirow{2}{*}{ Loneliness } & Low Self Esteem & 0.951 & 52 & 0.083 \\
\cline { 2 - 5 } & High Self Esteem & 0.954 & 55 & 0.065 \\
\hline
\end{tabular}

As seen in table 1 and 2, Test of normality of Shapiro - Wilk indicated that alpha level for loneliness of Indians in USA was 0.097 , which is more than 0.05 , hence null hypothesis is accepted and we can conclude that the sample of data of Indians in USA is normally distributed [4,5]. The significance level in Shapiro Wilk test for loneliness score of Indians was 0.082 , which is more than 0.05 , hence null hypothesis is accepted indicating that the sample of Indigenous Indians is normally distributed. The significance value in Shapiro Wilk test for loneliness in low self-esteem was 0.083 and high self-esteem was 0.065 . Since both the values are higher than the alpha level of 0.05 , it can be concluded that samples are normally distributed. As indicated in table 3, Levene's test of homogeneity of variances indicated significance of 
0.338 , hence it can be said that null hypothesis is accepted and error variance of dependent variable is equal across all groups.

Table 3 - Mean and SD values of all scores

\begin{tabular}{|c|c|r|r|c|}
\hline Country & Self_Esteem & Mean & $\begin{array}{c}\text { Standard } \\
\text { Deviation }\end{array}$ & $\mathrm{N}$ \\
\hline \multirow{3}{*}{$\begin{array}{c}\text { Indians in } \\
\text { USA }\end{array}$} & $\begin{array}{c}\text { Low Self } \\
\text { Esteem }\end{array}$ & 25.28 & 4.159 & 25 \\
\cline { 2 - 5 } & $\begin{array}{c}\text { High Self } \\
\text { Esteem }\end{array}$ & 18.40 & 3.731 & 25 \\
\cline { 2 - 5 } & Total & 21.84 & 5.231 & 50 \\
\hline Indians & $\begin{array}{c}\text { Low Self } \\
\text { Esteem }\end{array}$ & 17.67 & 2.815 & 27 \\
\cline { 2 - 5 } & $\begin{array}{c}\text { High Self } \\
\text { Esteem }\end{array}$ & 18.07 & 3.118 & 30 \\
\cline { 2 - 5 } & Total & 17.88 & 2.958 & 57 \\
\hline Total & $\begin{array}{c}\text { Low Self } \\
\text { Esteem }\end{array}$ & 21.33 & 5.189 & 52 \\
\cline { 2 - 5 } & $\begin{array}{c}\text { High Self } \\
\text { Esteem }\end{array}$ & 18.22 & 3.381 & 55 \\
\cline { 2 - 5 } & Total & 19.73 & 4.606 & 107 \\
\hline
\end{tabular}

Figure - Comparison of estimated means of loneliness for 4 different groups

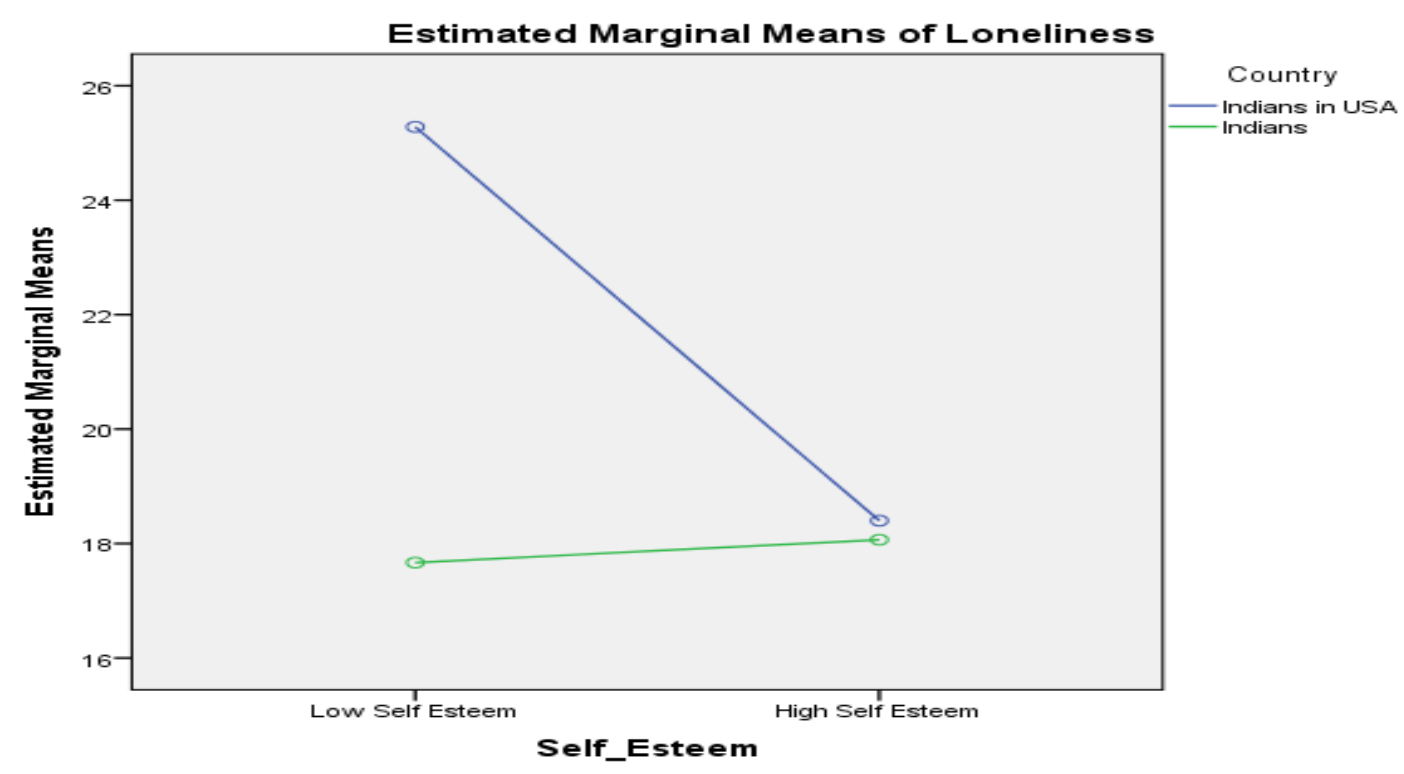

The $\mathrm{F}$ value for the independent variable of Culture was $33.431, \mathrm{p}<0.0001$, the $\mathrm{F}$ value for independent value of Self-esteem was 20.11, $\mathrm{p}<0.0001$ and the $\mathrm{F}$ value for the interaction effect, Culture* Self-esteem was $29.35, \mathrm{p}<0.0001$

\section{DISCUSSION}

The purpose of this study was to find if migration from collectivistic culture to individualistic culture made a difference in the reported loneliness and also if Self-esteem scores made a difference in reported loneliness. The mean loneliness score reported for Indians who had migrated to USA and with high selfesteem was 18.40 , while those who had migrated to USA but with low self-esteem was 25.28 . And the total mean of loneliness for Indians in USA was 21.84. The mean loneliness score for Indigenous Indians with high self-esteem was 17.67 , while those with low self-esteem was 18.07 . Hence the total mean score 
of loneliness was 17.87. The difference between the mean scores of Indians in USA and Indigenous Indians was significant with the $\mathrm{F}$ value of $33.43, \mathrm{p}<0.0001$. Similarly, the total mean scores of participants with high self-esteem was 18.23 and mean loneliness score of participants with low self-esteem was 21.47. The difference between the mean scores was significant with $F$ value of $20.11, p<0.0001$. There was also an interaction effect, whereby the Indians in USA with Low self-esteem had the highest loneliness score of 25.28 , followed by Indians in USA having high self-esteem 18.40, followed by Indians with high self-esteem in India 18.07 and lastly Indians with low self-esteem 17.67. The interaction effect was significant with $\mathrm{F}$ value of 29.35 , $\mathrm{p}<0.0001$.

Since all the $\mathrm{F}$ values are significant, both null hypothesis are rejected and alternative hypothesis were accepted. Hence reported loneliness is higher for Indians in USA compared to Indigenous Indians and reported loneliness is higher for participants with low self-esteem as compared to participants with high self-esteem. However, there is a significant interaction effect, whereby although high self-esteem acts as a buffer in reported feelings of loneliness in Indians shifted to USA, in Indigenous Indians, people with low high self-esteem actually report higher levels of self-esteem and people with low self-esteem report less feelings of loneliness.

As seen in figure 1, the lowest reported estimated mean of loneliness of Indians in USA is still higher than the highest reported mean of loneliness of Indigenous Indians. Also in India having high self-esteem actually increased the reported loneliness.

Self-esteem has been linked to loneliness in lot of studies [24]. It is sometimes viewed as an antecedent cause of loneliness. It is also possible that children who develop low self-esteem are likely to feel lonelier. Lot of different studies have linked low self-esteem to loneliness in adults as well as adolescents [25]. Researchers state that self-esteem being judgements about one's self, can affect the social interactions and behaviour. Individuals with high self-esteem enjoy more social interactions and hence even while growing up have many opportunities for normal socialization experiences. Even in this study is ids seen overall that having higher self-esteem does reduce the chances of feeling lonely [26].

In terms of culture, it is seen that individuals from individualistic culture report feeling morelonely than individuals from collectivistic cultures. It could be even worse for individuals who have grown up in a collectivistic environment and move to an individualistic culture. Studies have shown that individuals from collectivistic background have relationship in their perpetual forefront while individuals from individualistic culture have personal fulfilment as forefront of perception. Meeting people with such shift in perception could make Indians in USA construe people in individualistic culture as more selfish and hence end up feeling lonelier. This is seen in this study too [27].

The interaction effect shows that indigenous Indians with high self-esteem actually report feeling lonelier than Indigenous Indians with low self-esteem. Since India is a Vertical Collectivistic culture, where individuals from lower hierarchy groups are considered extremely unimportant to authority figures having high self-esteem may make it difficult to confirm to authority figures as expected out of them. Hence, they may have reported higher loneliness rather than Indigenous Indians with low self-esteem who may have no qualms about confirming to higher authority and hence feel that they get along, belong and hence feel less lonely.

\section{Limitations of the study and suggested improvements}

The biggest limitation of the study was its sample size and the convenience sampling method. This study can be replicated with larger sample size and also random sampling method. Also all individuals participating in the study from USA were taken from state of New York. New York is a more metropolitan city with more heterogeneous environment, with individuals from lot of different nationalities and backgrounds. Hence the reported loneliness levels may not be reflective of Indians staying in more remote areas of USA, where the population is more homogenous. The study also just utilized questionnaire without corresponding interview. Some form of interview method could have been utilized to understand better the causes of loneliness. 


\section{CONCLUSION}

It is concluded from this study that in this sample, Indians in USA reported feeling more lonely than Indigenous Indians, while participants with lower self-esteem reported feeling lonelier than individuals with high self-esteem, with interaction effect whereby people with high self-esteem actually reported feeling more lonely in Indian than people with low self-esteem.

\section{REFERENCES \& FURTHER READING}

1. Rokach A, Neto F. Age, culture, and the antecedents of loneliness. Soc Behav Personality 2005;33(5):477-94.

2. Anderson CA. Attributional style, depression, and loneliness: A cross-cultural comparison of American and Chinese students. Personal Soc Psychol Bull 1999;25(4):482-99.

3. Rokach A. The effect of age and culture on the causes of loneliness. Soc Behav Personal 2007;35(2):169-86.

4. Goodwin R, Cook O, Yung Y. Loneliness and life satisfaction among three cultural groups. Personal Relat 2001;8(2):225-30.

5. Seepersad S, Choi MK, Shin N. How does culture influence the degree of romantic loneliness and closeness?. J Psychology 2008;142(2):209-20.

6. Ward C, Rana-Deuba A. Home and host culture influences on sojourner adjustment. Int J Intercultural Relat 2000;24(3):291-306.

7. van Staden WC, Coetzee K. Conceptual relations between loneliness and culture. Curr Opin Psychiatry 2010;23(6):524-9.

8. Sawir E, Marginson S, Deumert A, Nyland C, Ramia G. Loneliness and international students: An Australian study. J Stud Int Educ 2008;12(2):148-80.

9. Rokach A, Neto F. Coping with loneliness in adolescence: A cross-cultural study. Social Behav Personal 2000;28(4):329-41.

10. Cacioppo JT, Patrick W. Loneliness: Human nature and the need for social connection. WW Norton \& Company; 2008.

11. Shin Y. Peer relationships, social behaviours, academic performance and loneliness in Korean primary school children. School Psychol Int 2007;28(2):220-36.

12. Berk LE. Child development. Pearson; 2007.

13. Al Khatib SA. Exploring the relationship among loneliness, self-esteem, self-efficacy and gender in United Arab Emirates college students. Eur J Psychol 2012;8(1):159-66.

14. Kirsh SJ, Duffy KG, Atwater E. Psychology for Living: Adjustment, Growth, and Behavior Today. Pearson; 2014.

15. Ma ZW, Liang JJ, Zeng WN, Jiang S, Liu T. The Relationship Between Self-Esteem and Loneliness: Does Social Anxiety Matter?. Int J Psychol Stud 2014;6(2):151-8.

16. Rokach A. Loneliness updated: Recent research on loneliness and how it affects our lives. Routledge; 2013.

17. Sorrentino RM, Cohen D, Olson JM, Zanna MP. Culture and social behavior: The Ontario symposium. Psychology Press; 2005.

18. Ellison CW. The Roots of Loneliness. Christianity Today. 1978;22(11):12-6.

19. Brown L, Holloway I. The initial stage of the international sojourn: excitement or culture shock?. Br J Guid Couns 2008;36(1):33-49.

20. Fiske ST, Taylor SE. Social cognition: From brains to culture. Sage; 2013.

21. O'nell TD. Culture and pathology: Flathead loneliness revisited. Culture Med Psychiatry 2004;28(2):221-30.

22. Robins RW, Hendin HM, Trzesniewski KH. Measuring global self-esteem: Construct validation of a singleitem measure and the Rosenberg Self-Esteem Scale. Personal Soc Psychol Bull 2001;27(2):151-61.

23. Russell DW. UCLA Loneliness Scale (Version 3): Reliability, validity, and factor structure. J Personal Assess 1996;66(1):20-40.

24. Heinrich LM, Gullone E. The clinical significance of loneliness: A literature review. Clin Psychol Rev 2006;26(6):695-718.

25. Cacioppo JT, Hughes ME, Waite LJ, Hawkley LC, Thisted RA. Loneliness as a specific risk factor for depressive symptoms: cross-sectional and longitudinal analyses. Psychol Aging 2006;21(1):140-8.

26. Hawkley LC, Cacioppo JT. Loneliness matters: a theoretical and empirical review of consequences and mechanisms. Ann Behav Med 2010;40(2):218-27.

$* * * * * * * * * * * * * * * * * * * * * * * * *$

Acknowledgements - Nil ; Conflict of Interest - Nil; Funding - Nil

Indian Journal of Mental Health 2018;5(1) 